\title{
WORKSHOP SENI LUKIS TINGKAT SEKOLAH MENENGAH ATAS DAN SEKOLAH MENENGAH KEJURUAN SEDERAJAT DI KOTA PALEMBANG
}

\author{
Husni Mubarat \\ Muhammad Idris lail \\ Program Studi Desain Komunikasi Visual, Fakultas Ilmu Pemerintahan dan Budaya, \\ Universitas Indo Global Mandiri \\ Jln. Jend. Sudirman No. 629 Km. 4 Kota Palembang \\ Husnidkv@uigm.ac.id \\ iyesart21@gmail.com
}

\begin{abstract}
ABSTRAK
Kegiatan workshop seni lukis tingkat SMA dan SMK sederajat di Kota Palembang dengan tema "Pesona Perempuan Palembang Dalam Lukisan" terlaksana atas kerjasma antara Museum Basoeki Abdullah dengan Museum Balaputra Dewa Negeri Sumatera Selatan, yang dilaksanakan pada hari Kamis, 12 November 2020. dilakukan secara berkala setiap tahun dengan mengusung tema yang berbeda-berbeda, namun tetap dalam bingkai ke-Indonesiaan, baik dari aspek sosialnya maupun dari aspek budaya. Kegiatan ini melukiskan pesona perempuan Palembang dalam ragam pakaian tradisional. Adapun tujuan kegiatan workshop adalah untuk memberikan wawasan dan keterampilan melukis bagi remaja, memperkenalkan Sosok Basoeki Abdullah beserta Museumnya, dan memperkenalkan kembali pakaian tradisional perempuan Palembang di masa lampau. Kegiatan workshop ini menggunakan metode presentasi materi, demonstrasi, bimbingan, dan evaluasi. Adapun hasil workshop adalah karya lukisan akrilic di atas kertas $40 \mathrm{~cm} \times 60 \mathrm{~cm}$, dengan mengusung gaya realis dan naturalis. Diharapkan kegiatan ini dapat menstimulus peserta untuk mempelajari seni lukis lebih jauh lagi dengan harapan munculnya generasi muda seniman lukis, khususnya di Kota Palembang.

Kata Kunci: Lukisan; Perempuan Palembang; Basoeki Abdullah; Museum
\end{abstract}




\section{Jurnal Batoboh, Vol 5, No 2, Oktober 2020 \\ Husni Mubarat \\ Muhammad Idris lail}

\section{PENDAHULUAN}

Salah satu aspek yang melingkupi kehidupan manusia adalah kesenian, karena dengan kesenianlah manusia dapat meresapi rasa dan nilai-nilai keindahan, baik yang tercipta melalui keindahan alam (ciptaan yang Maha Kuasa) maupun nilai-nilai keindahan yang diciptakan oleh manusia itu sendiri dengan berbagai macam media. Walaupun tidak semua manusia dapat menciptakan karya seni, namun semua manusia tentunya dapat menikmati hasil karya seni dengan segala bentuk keindahannya, salah satunya adalah seni lukis.

Seni lukis sendiri adalah seni rupa yang cukup banyak digandrungi oleh masyarakat. Ada yang belajarnya secara otodidak adapula yang belajar melalui lembaga pendidikan, baik yang setara dengan tingkat SMA dan SMK maupun tingkat Perguruan Tinggi.

Indonesia sendiri telah banyak melahirkan seniman-seniman lukis dengan berbagai aliran dan gaya lukisan, mulai dari Raden Saleh,
Affandi, Sudjojono, Basoeki Abdullah dan seniman-seniman yang melegenda lainnya. Salah satu seniman legenda yang banyak dikenal oleh masyarakat Hal| 140 adalah Basoeki Abdullah. Kiprahnya di dunia seni lukis tidak dapat diragukan lagi, bahkan rumahnya sendiri dihibahkan kepada bangsa Indonesia untuk dijadikan museum. Ini membuktikan bahwa ia memiliki niat yang baik agar dikemudian hari akan tumbuh seniman-seniman lukis muda Indonesia yang tidak hanya kreatif, tetapi juga memiliki jiwa dan rasa nasionalis yang tinggi. Hal tersebutlah yang kemudian menjadi salah satu misi dari Museum Basoeki Abdullah untuk selalu berupaya menumbuhkan generasi seniman lukis di Indonesia, salah satunya adalah Workshop Lukis yang bekerjasama dengan museummuseum yang ada di Indonesia, seperti Museum Balaputra Dewa Negeri Sumatera Selatan.

Kegiatan Workshop dilakukan secara berkala setiap tahun dengan mengusung tema yang berbeda- 


\section{Jurnal Batoboh, Vol 5, No 2, Oktober 2020 \\ Husni Mubarat \\ Muhammad Idris lail}

berbeda, namun tetap dalam bingkai ke-Indonesiaan, baik dari aspek sosialnya maupun dari aspek budaya. Tema-tema tersebut tidak lain adalah sebagai upaya untuk menumbuhkan generasi seniman-seniman muda yang peka terhadap sosial dan budaya bangsa Indonesia.

Pada tahun ini Museum Basoeki Abdullah mengangkat tema tentang "Sosok Perempuan Indonesia" yang kemudian pada workshop lukis di Museum Balaputra Dewa Negeri Sumatera Selatan diberi tema "Pesona Perempuan Palembang dalam Lukisan" yang dikuti oleh 50 pelajar dari berbagai sekolah yang ada di Kota Palembang, baik dari tingkat SMA maupun SMK sederajat.

Kegiatan ini melukiskan pesona perempuan Palembang dalam ragam pakaian tradisional. Tema ini melukiskan bagaimana peran perempuan Palembang di tengah kehidupan sosial dan budaya, utamanya adalah perempuan sebagai sosok seorang ibu, yang tentunya memiliki peran dan jasa yang tidak terhitung dalam kehidupan masyarakat.

Secara garis besar, kegiatan ini Hal| 141 bertujuan (1) memperkenalkan seni lukis di tingkat pelajar SMA dan SMK sederajat baik secara teknik maupun wacana, (2) untuk memperkenalkan sosok dan sejarah Basoeki Abdullah sebagai salah satu legenda seniman lukis Indonesia, (3) untuk memperkenalkan kembali pakaianpakaian tradisional perempuan Palembang di masa lampau yang sudah sangat jarang digunakan pada saat sekarang ini, (4) melalui tema ini diharapkan dapat membangun rasa empaty terhadap pelajar agar menghormati dan menyayangi sosok seorang ibu. Adapun manfat yang diharapkan dari kegiatan ini di antaranya adalah: (1) peserta pelatihan diharapkan dapat memahami teori dan praktek dalam berkarya seni lukis, (2) peserta diharapakan dapat memahami sosok dan sejarah Basoeki Abdullah serta keberadaan museumnya, 


\section{Jurnal Batoboh, Vol 5, No 2, Oktober 2020 \\ Husni Mubarat \\ Muhammad Idris lail}

peserta pelatihan diharapkan dapat memahami budaya lokal melalui pakaian tradisi perempuan Palembang.

Kegiatan workshop seni lukis ini juga mencerminkan peran Museum Balaputra Dewa Negeri Sumatera Selatan dalam upaya melestarikan artefak-artefak budaya ataupun kearifan lokal Sumatera Selatan di masa lampau agar tetap lestari dan dapat dipelajari oleh generasi millenial. Sebagai bagian dari kaum akademisi tentu memiliki kewajiban dan berkomitmen untuk melaksanakan pengabdian terhadap masyarakat secara berkala. Hal ini bertujuan untuk memberikan wawasan dan mengembangkan keterampilan bagi masyarakat di Kota Palembang (Mubarat \& Ilhaq, 2019).

Adapun metode workshop "Pesona Perempuan Palembang dalam Lukisan" di antaranya adalah adalah: (1) Pemaparan Materi. Metode ini dilakukan dengan cara presentasi materi, yaitu mengenal sosok dan sejarah Museum Basoeki Abdullah, mengenalkan beberapa karya-karya lukisan Basoeki Abdullah, dan materi tentang dasar-dasar dalam melukis, (2) Metode Demonstrasi, yaitu nara sumber praktek secara langsung Hal| 142 tentang bagaimana membuat lukisan dengan gaya realis, mulai dari pembuatan sketsa hingga proses mewarnai, (3) Metode Bimbingan, yaitu peserta dibimbing oleh narasumber secara langsung dalam proses melukiskan perempuan Palembang dengan pakaian tradisional. Sebelum proses workshop melukis dimulai, masing-masing peserta dibagikan gambar-gambar tentang perempuan Palembang yang menggunakan pakaian tradisional, (4) Proses Evaluasi. Setelah workshop selesai, proses evaluasi dilakukan dengan cara berdiskusi bersama peserta, baik tentang teknik sketsa maupun teknik melukis atau proses mewarnai. Masing masalah yang dihadapi oleh para peserta diberikan solusi oleh para nara sumber, sehingga pemecahan masalah tersebut dapat menjadi pelajaran bagi peserta untuk ke depannya. 


\section{Jurnal Batoboh, Vol 5, No 2, Oktober 2020 \\ Husni Mubarat \\ Muhammad Idris lail}

PEMBAHASAN

Materi Teori Seni Lukis

"Pada dasarnya seni lukis

merupakan bahasa ungkap dari pengalaman estetik maupun ideologis yang menggunakan garis dan warna guna mengungkapkan

perasaan, mengekspresikan emosi, gerak, ilusi maupun ilustrasi dari kondisi subjektif seseorang" (Susanto, 2011). Berangkat dari kutipan tersebut, perlu kiranya penulis sampaikan bahwa materi yang dijelaskan dalam kegiatan workshop seni lukis dengan tema "Pesona Perempuan Palembang dalam Seni Lukis" tidak memaparkan materi dari berbagai perspektif teori seni lukis. Materi dalam kegiatan ini difokuskan hanya pengenalan gaya lukisan yang bersifat realis dan naturalis. Materi ini disusun berdasarkan gaya dan teknik lukisan Basoeki Abdullah, dimana kecenderungannya lebih mengarah pada gaya lukisan realis dan naturalis. Gaya lukisan realis dapat diartikan sebagai gaya lukisan yang memandang apa adanya tanpa menambah dan mengurangi objek yang divisualisasikan pada media lukis (Susanto, 2011). Sementara itu gaya naturalis dapat diartikan sebagai "gaya Hal| 143 seni yang merupakan representasi yang bertujuan untuk mereproduksi objek sebagai keyakinan atas alam" (Susanto, 2011).

Istilah realisme dan naturalisme dalam dunia seni lukis, sering kali digunakan untuk menggambarkan objek sebagaimana adanya. Hal yang membedakan antara realisme dan naturalisme adalah adanya kecenderungan lukisan dengan gaya naturalis lebih memperindah objek dari bentuk yang sebenarnya().

\section{Sejarah Singkat Museum Basoeki}

\section{Abdullah}

Basoeki Abdullah dilahirkan di Solo Jawa Tengah pada tanggal 27 Januari. Bakat melukisnya terwarisi dari ayahnya, Abdullah Suryosubroto yang juga sempat mencatat namanya dalam sejarah seni lukis Indonesia. Pada usia 10 tahun, Basoeki Abdullah telah melukis Mahatma Gandhi dengan 


\section{Jurnal Batoboh, Vol 5, No 2, Oktober 2020}

Husni Mubarat

Muhammad Idris lail

menggunakan pensil di atas kertas yang hasilnya sangat luar biasa untuk ukuran anak seusia itu.

Pendidikan formal Basoeki Abdullah diperoleh melalui HIS (Hollan Inlansche School). Pada tahun 1933ia memperoleh beasiswa untuk belajar di akademi seni rupa (Academic Van Beldeende Kunsten) di Denhag Belanda (Munandar, Agus Aris, 2009).

Bila lihat secara keseluruhannya, lukisan Basoeki Abdullah terdiri dari beberapa tema, yaitu mulai dari tema perjuangan, tema sosial dan kemanusiaan dan tema-tema yang berkaitan dengan alam dan pemandangan.

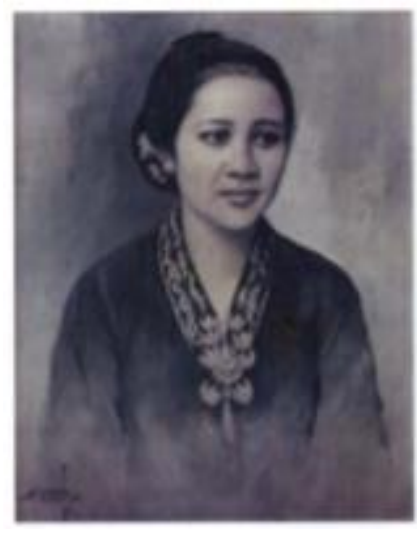

Gambar 1.

Raden Ajeng Kartini, Repro di atas kertas $76 \mathrm{~cm}$ x 60 cm, 1976. Koleksi Museum Basoeki Abdullah
Berkaitan dengan sejarah Museum Basoeki Abdullah diawali setelah kematian pelukis Basoeki Abdullah pada tahun 1993, rumah Hal| 144 pribadinya yang terletak di $\mathrm{Jl}$. Keuangan Raya No. 19 Cilandak Barat, Jakarta Selatan, diserahkan pihak keluarga kepada Pemerintah Republik Indonesia melalui Direktorat Jendral Kebudayaan cq. Direktorat Permuseuman, untuk dijadikan museum. Rumah tersebut kemudian direnovasi pada tanggal 25 September 2001, dan resmi beralih fungsi menjadi Museum Basoeki Abdullah, dan diresmikan oleh Menteri Kebudayaan dan Pariwisata saat itu, Drs. I Gede Ardika. (Sumber: Dra. Maeva Salmah, kepala Museum Basoeki Abdullah, 12 November 2020).

Adapun fungsi Museum Basoeki Abdullah, yaitu:

1. Pengkajian benda bernilai seni dan karya tokoh Basoeki Abdullah, 


\section{Jurnal Batoboh, Vol 5, No 2, Oktober 2020 \\ Husni Mubarat \\ Muhammad Idris lail}

2. Pengumpulan benda bernilai

10. Pelaksanaan

urusan seni dan karya tokoh Basoeki Abdullah

ketatausahaan Museum Basoeki Abdullah.

3. Pelaksanaan registrasi dan Perempuan Palembang dalam Pakaian Hal| 145 dokumentasi benda seni dan Adat karya tokoh Basoeki Abdullah,

Sosok perempuan adalah figur

4. Perawatan benda bernilai seni yang memiliki peran dan posisi penting dan karya tokoh Basoeki Abdullah,

5. Pelaksanaan pengamanan benda bernilai seni dan karya tokoh Baseki Abdullah,

6. Pelaksanaan penyajian dan publikasi benda bernilai seni dan karya tokoh Basoeki Abdullah,

7. Pelaksanaan layanan edukasi di bidang benda bernilai seni dan karya tokoh Basoeki Abdullah,

8. Pelaksanaan kemitraan di bidang benda bernilai seni dan karya tokoh Basoeki Abdullah,

9. Fasilitasi pengkajian, pengumpulan, perawatan, pengamanan, penyajian dan layananedukasi di bidang benda bernilai seni dan karya tokoh Basoeki Abdullah, dalam kehidupan manusia, baik dalam konteks sosial maupun dalam konteks budaya. Eksistensi perempuan tidak hanya dikenal sebagai figur yang lembut dan penyayang, lebih dari itu figur seorang perempuan juga dikenal sebagai sosok seorang ibu yang sangat memiliki peran yang besar dan sosok kehormatan dalam kehidupan manusia, baik keluarga maupun bangsa dan negara. Begitu pula dalam konteks budaya, yang mana sosok perempuan menjadi bagian dari entitas bagi suatu daerah, bangsa, dan adat istiadat.

Demikian pula halnya dengan sosok perempuan Palembang, kehadirannya tidak terlepas dari simbol kehormatan bagi kehidupan masyarakatnya, sehingga ia mendapatkan tempat yang istimewa 


\section{Jurnal Batoboh, Vol 5, No 2, Oktober 2020 \\ Husni Mubarat \\ Muhammad Idris lail}

dalam kehidupan budaya melalui pakaian-pakaian adat tradisional yang didesain secara khusus, terutama dalam bentuk songket yang biasanya digunakan sebagai pakaian perkawinan.

Menurut Supriyanto \& Sari, (2017) mengungkapkan bahwa:

"Songket palembang merupakan kain tradisional palembang yang cara pembuatannya ditenun oleh wanita-wanita palembang. Keberadaan kain songket menunjukkan sebuah tingkat kebudayaan yang tinggi, sebabdalam kain ini tersimpan berbagai hal seperti bahan yang digunakan, cara pengerjaan, makna yang terkandung didalamnya sekaligus cara penggunaanya dan tingkatan orang memakainya".

Selanjutnya (Tifanny et al., 2019) mengungkapkan bahwa:

"Sejak dulu songket lebih banyak dikenakan oleh kaum perempuan yang dipadankan dengan baju kurung panjang. Untuk busana pengantin, songket yang dipakai adalah songket dengan benang emas yang penuh. Songket yang dikenakan dipernikahan yaitu motif songket lepus. Songket lepus ini songket yang pertama ada di Palembang. Selain itu, songket ini juga merupakan pakaian para Raja dan Ratu zaman kerajaan Sriwijaya pada saat itu".

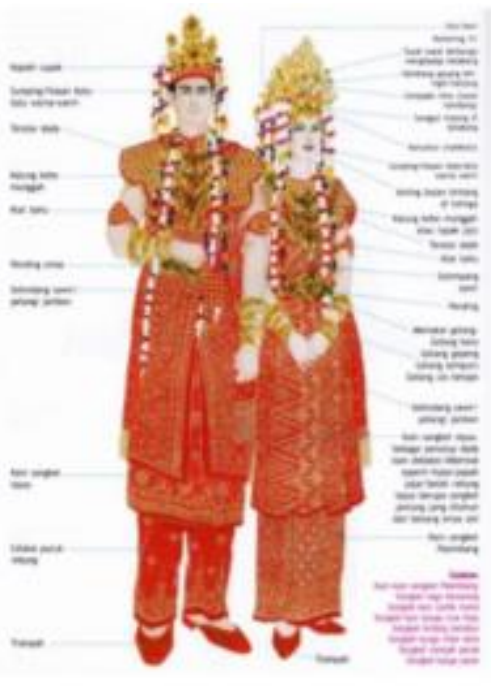

Hal| 146

Gambar 2.

Pakaian Adat Palembang

(Sumber: Dokumentasi; (Tifanny et al., 2019)

Proses dan Tahapan Kegiatan Melukis

Proses dan tahapan kegiatan dalam pelaksanaan kegiatan workshop lukis di antaranya adalah:

1. Proses Sketsa

Sketsa adalah materi tahap pertama yang disampaikan kepada peserta. Oleh karena itu penting kiranya untuk meberikan pemahaman kepada peserta bahwa sketsa adalah salah satu bagian yang perlu dipelajari oleh peserta, karena peranan sketsa dalam melukis sangat menentukan 
hasil dari sebuah lukisan, terutama pada aspek bentuk, seperti wajah, anatomi dan assesoris pendukung yang ada pada objek. Selain itu sketsa juga berperan untuk mengamati wujud secara keseluruhan dari lukisan yang akan dibuat, baik proporsionalnya maupun perspektif.

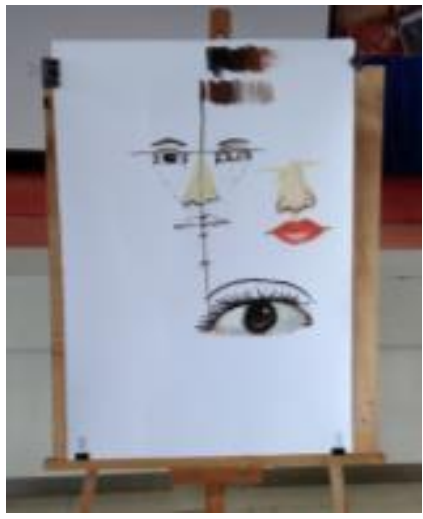

Gambar 3.

Contoh Teknik Sketsa Wajah (Foto: Dokumentasi; Wisnu, 2020)

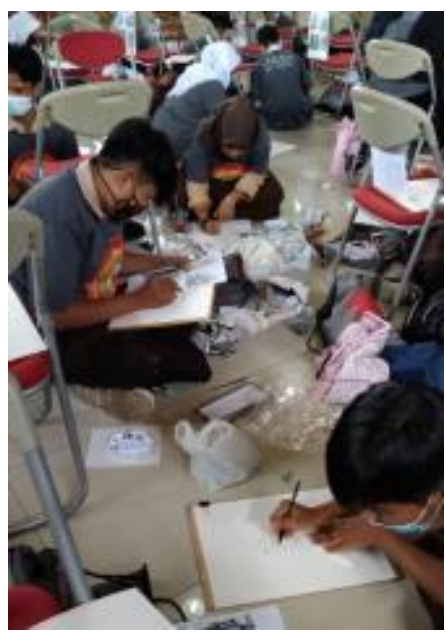

Gambar 4.

Proses Pembuatan Sketsa

(Foto: Dokumentasi; Wisnu, 2020)

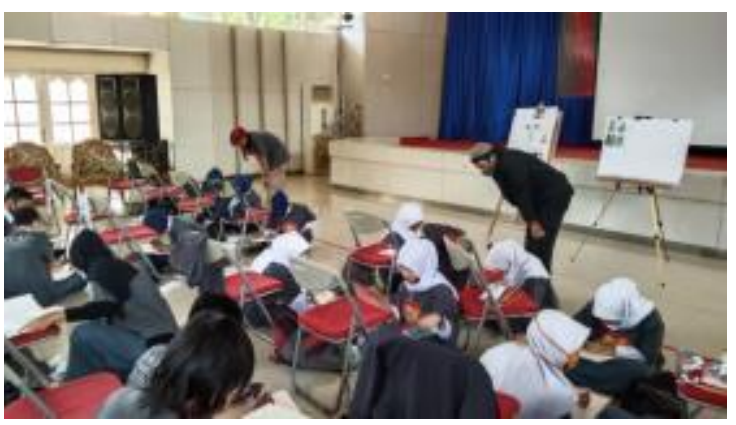

Hal 147

Gambar 5.

Proses Pembimbingan Pembuatan Sketsa

(Foto: Dokumentasi; Wisnu, 2020)

2. Proses Warna

Pewarnaan dalam lukisan merupakan bagian yang tidak dapat dipisahkan dari kegiatan melukis. Selain sebagai bagian dari elemen dalam seni rupa, eksistensi warna berperan sebagai pembentuk dimensi, ruang (volume), dan gelap terang pada karya lukisan. Kehadiran warna pada lukisan kerap pula menjadi bagian dari nilai estetik dan simbol serta nilai makna yang dihadirkan. Oleh karena itu penting kiranya untuk memberi pengetahuan kepada peserta tentang teknik pengolahan warna pada lukisan, baik cara mencampurkan warna maupun pengenalan jenis cat yang digunakan. Dalam kegiatan ini peserta menggunakan cat jenis akrilic. 


\section{Jurnal Batoboh, Vol 5, No 2, Oktober 2020}

Husni Mubarat

Muhammad Idris lail

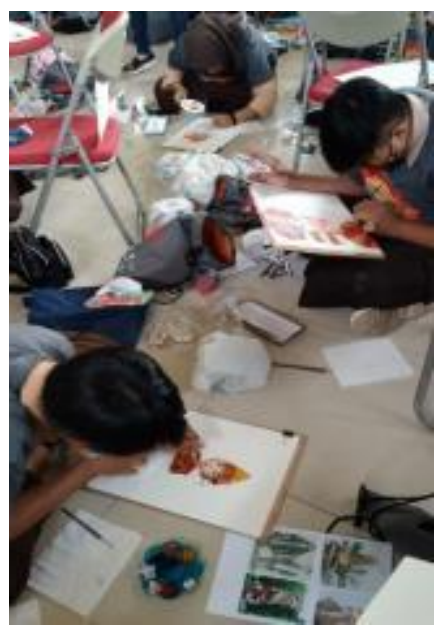

Gambar 6.

Proses Mewarnai Lukisan

(Foto: Dokumentasi; Wisnu, 2020)

\section{Tahap Finishing}

Tahap ini merupakan bagian akhir dalam worksho seni lukis. Bagian ini memberikan keterampilan dan pengetahuan kepada peserta apa saja bagian-nagian dari lukisan yang perlu untuk difinishing.

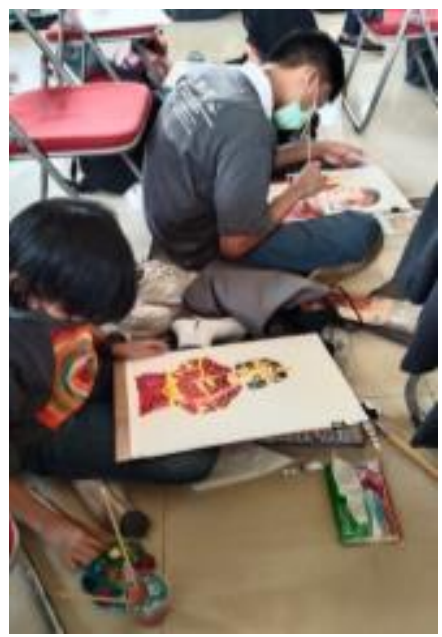

Proses Finishing Lukisan

(Foto: Dokumentasi; Wisnu, 2020)
Secara teknisnya setelah peserta menyelesaikan lukisannya secara keseluruhan, peserta tersebut diminta untuk mengamati karya lukisnya Hal| 148 masing dengan jarak lebih kurang 1 meter. Dalam proses pengamatan itu, peserta kemudian diarahkan untuk melihat secara detail, kira-kira bagian mana yang perlu diperbaiki maupun yang perlu ditambahkan, sehingga lukisan yang dibuat dapat menghasilkan karya yang maksimal.

\section{Hasil Kegiatan Workshop}

Untuk kegiatan workshop seni lukis ini disadari bahwa durasi yang ditentukan sangatlahlah terbatas, sehingga hasil kegiatan ini tidak dapat menjadi ukuran keberhasilan bagi peserta dalam menguasai teknik melukis. Tentunya dapat dipahami bahwa untuk menjadi seorang pelukis tidak dapat dicapai dalam proses tempo yang singkat, melainkan dibutuhkan waktu yang panjang dan proses yang intens dalam menguasai teknik melukis. Akan tetapi terlepas 


\section{Jurnal Batoboh, Vol 5, No 2, Oktober 2020}

Husni Mubarat

Muhammad Idris lail

dari faktor tersebut, tentunya capaian dalam kegiatan ini setidaknya dapat menstimulus terhadap peserta sebagai generasi yang memiliki minat untuk belajar melukis. Harapannya peserta dapat meneruskan latihannya untuk belajar melukis melalui bimbingan instruktur.

Bila

diamati

secara

keseluruhannya, hasil yang dicapai oleh peserta workshop cukup memuaskan, dengan bekal peserta yang secara keseluruhan latar belakang pendidikanya bukanlah berasalah dari pendidikan seni rupa, melainkan dari pendidikan umum dan kejuruan. Melalui kegiatan ini dapat dipahami bahwa sesungguhnya minat pelajar terhadap seni, terkhususnya seni lukis sangat antusias.

Secara faktual, kegiatan workshop tersebut dapat diyakini bahwa kegiatan ini layak menjadi pertimbangan bagi pemerintah terkait untuk mewadahi dari minat dan bakat para pelajar, khusus daerah Sumatera Selatan (Palembang) untuk didirikan lembaga
Perguruan tinggi Seni agar para pelajar yang memiliki minat terhadap seni dapat diwujudkan.

Adapun karya-karya lukisan Hal| 149 dalam kegiatan workshop yang dihasilkan adalah sebagai berikut:
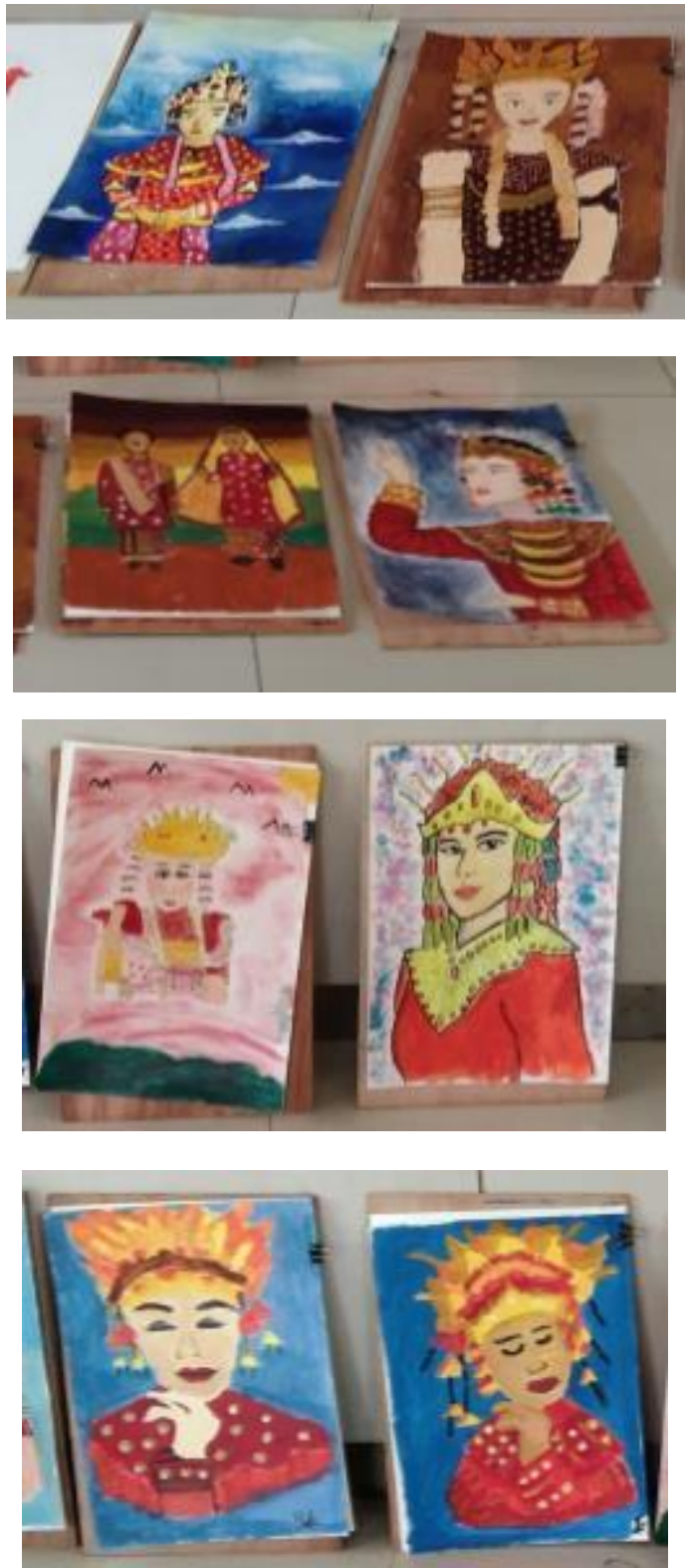


\section{Jurnal Batoboh, Vol 5, No 2, Oktober 2020 \\ Husni Mubarat \\ Muhammad Idris lail}

\section{SIMPULAN}

Dari keseluruhan rangkaian kegiatan workshop melukis tingkat SMA dan SMK sederajat, dapat dikatakan berjalan dengan lancar. Terlihat semua peserta mengikuti kegiatan tersebut sangat antusias, karena mungkin sebahagian dari peserta, kegiatan melukis ini merupakan pengalaman yang menarik bagi masing-masing peserta, khususnya peserta yang baru belajar melukis.

Di samping pengalaman kegiatan ini sebagai bagian dari sejarah individu dari masing-masing peserta, kegiatan workshop melukis ini juga memberikan pengalaman estetik bagi setiap peserta sebagai bagian dari ekspresi dan refresentasi terhadap tema lukisan yaitu “Pesona Perempuan Palembang Dalam Lukisan".

Dari kegiatan tersebut dapat pula disimpulkan bahwa masing-masing peserta memperoleh ilmu pengetahuan baik dari segi wacana seni lukis, sejarah Museum Basoeki Abdullah, maupun wawasan kebudayaan lokal Palembang di masa lampau.

Bila

diamati secara

keseluruahnnya, patut diakui bahwa Hal| 150 hasil kegiatan workshop lukisan ini masih terdapat kekurangan, terutama pada aspek sketsa dan capaian bentuk yang realis. Akan tetapi patut pula dipahami bahwa sebagai pemula tentunya peserta tersebut butuh proses yang lebih intens lagi untuk bisa menguasai teknik-teknik melukis. Apalagi kegiatan ini durasi waktunya sangat terbatas sehingga sebahagian dari peserta tidak dapat menyelesaikan lukisannya.

Oleh sebab itu diharapkan kegiatan ini dapat menjadi batu loncatan bagi peserta untuk belajar melukis secara intens. Selanjutnya diharapkan juga kepada guru-guru pembimbing dapat memberi fasilitas dan wadah bagi pelajar di sekolah untuk menuangkan bakat dan minatnya di bidang seni lukis.

Tidak luput pula harapan ini disampaikan terhadap pihak Museum 
Jurnal Batoboh, Vol 5, No 2, Oktober 2020

Husni Mubarat

Muhammad Idris lail

Basoeki Abdullah dan Museum

kegiatan workshop, sehingga tujuan

Balaputra Dewa Negeri Sumatera kegiatan ini untuk melahirkan pelukis

Selatan, agar kegiatan ini dapat generasi muda, khususnya di

dilakukan secara berkesinambungan Palembang dapat terwujud. Hal| 151

dengan menambah porsi durasi

\section{KEPUSTAKAAN}

Mubarat, H., \& Ilhaq, M. (2019). Pelatihan Eksplorasi Jerami Menjadi Karya Seni Patung Di Martapura Ogan Komering Ulu Timur Sumatera Selatan. Batoboh, 4(1), 44. https://doi.org/10.26887/bt.v4i1.701

Munandar, Agus Aris, et. a. (2009). Lukisan Basoeki Abdullah; Tema, Dongeng, Legenda, Mitos dan Tokoh. Museum Basoeki Abdullah.

Supriyanto, \& Sari, N. R. (2017). Songket aesan gede sebagai pakaian adat perkawinan tradisional palembang (1966-1986). Jurnal Criksetra, 6(11), 22-29.

Susanto, M. (2011). Diksi Rupa. DictiArt Lab.

Tifanny, V., Rizali, N., Rudiyanto, G., Pada, A., Pernikahan, U., Palembang, A., Tapis, K., Utara, S., Tenun, K., Sikek, P., \& Palembang, S. (2019). Busana Pengantin Aesan Gede ( Tenun Songket Dan Sumatera Selatan. 1(2), 213-222. 